\title{
A EVOLUÇÃO LEGAL E INSTITUCIONAL NA GESTÃO DOS RECURSOS HÍDRICOS NO BRASIL
}

\author{
Maria José Andrade da Silva ${ }^{(a)}$ \\ (a) Departamento de Pós-Graduação em Geografia Humana. FFLCH-USP. E-mail: mjandrade2012@gmail.com
}

\section{EIXO: BACIAS HIDROGRÁFICAS E RECURSOS HÍDRICOS: ANÁLISE, PLANEJAMENTO E GESTÃO}

\section{Resumo}

O objetivo deste artigo é tecer considerações sobre os instrumentos legais de gestão dos recursos hídricos no Brasil, e observar os avanços que tem tido nesse campo. No decorrer do tempo, foram criados diversos instrumentos de gestão hídrica no Brasil, como o Código das Águas. A questão hídrica também foi sendo tratada nas diversas Constituições brasileiras, (1824 a 1988). Nesse sentido, é notório os avanços trazidos na Constituição Federal de 1988 sobre a gestão das águas, é a primeira a assegurar as águas como sendo um bem público. Somando-se a isso, foram criados a Lei das Águas e o Sistema Nacional de Gerenciamento dos Recursos Hídricos. A partir disso, a gestão das águas passou a ser descentralizada, democrática e integrada. Para nortear esta pesquisa, optou-se por consultar às Constituições brasileiras e os instrumentos de gestão hídrica que foram criados. Também far-se-ão leituras à luz da bibliografia existente sobre o assunto.

Palavras-chave: Bacias hidrográficas, gestão das águas, comitês de bacia

\section{Introdução}

A criação de leis voltadas para a gestão de recursos hídricos foi sendo ampliada e aprimorada, à medida que o consumo de água-doce foi aumentando nas indústrias, no setor energético e na população. Embora o Brasil concentre uma reserva de água-doce estimada em 12\% das reservas do planeta, existem grandes disparidades na distribuição das águas superficiais no país. Conforme os dados da Agência Nacional de Águas-ANA (2011, p. 12), "apesar de o Brasil possuir grande oferta de água em termos globais, existe uma distribuição desigual dos recursos hídricos". Destaca-se grande disponibilidade hídrica na Amazônia, com cerca de $81 \%$, que é onde se situa a menor densidade demográfica, com cerca de $8 \%$ da população brasileira. O restante dos $19 \%$ de água fica circunscrito ao abastecimento das outras áreas do território. Destacam-se as regiões sudeste e nordeste, que apresentam apenas $6 \%$ e $3 \%$ respectivamente das reservas, concentrando o maior número de habitantes do país. (IBGE, 2010). Diante disso, os conflitos pela água foram surgindo, em especial após a década de 1970, entre os usuários de água com a construção de barragens. Além disso, foi constatado que os padrões correntes de uso dos recursos hídricos eram vulneráveis; ao mesmo tempo em que houve o reconhecimento de que a água é um bem vital para todos os 
seres vivos e um dos principais recursos para o desenvolvimento dos países. Assim, foi necessário criar novos instrumentos de gestão hídrica que se adequassem à realidade do país.

A Constituição de 1988 foi inovadora, propôs um novo modelo de gestão dos recursos hídricos, de modo integrado e ao mesmo tempo descentralizado, tendo a bacia hidrográfica como unidade administrativa e órgãos colegiados, em diferentes níveis, como instâncias decisórias. Essa prerrogativa foi atendida, com a promulgação da Lei das Águas (8 de janeiro de 1997, Lei Federal n ${ }^{9} .433$ ).

Para aprofundar o entendimento sobre esse assunto, este artigo discorrerá sobre a gestão das águas. Inicialmente, será apresentado um resumo dos primeiros instrumentos de gestão hídrica no Brasil, em seguida serão discutidos os principais aspectos da gestão sobre os recursos hídricos que vigoram atualmente no país, acentuando o papel da União, dos Estados e do Distrito Federal no gerenciamento dos recursos hídricos em toda a federação brasileira.

\section{Gerenciamento dos recursos hídricos no Brasil}

Os instrumentos de gestão dos recursos hídricos no Brasil correspondem ao que tem sido estabelecido pela legislação oficial. (Ribeiro, 2010). Mas nem sempre foi assim, pois por muito tempo existiu o que se chama "águas privadas" - o controle sobre as reservas de água-doce esteve sob o comando dos primeiros núcleos urbanos, engenhos, fazendas e fortificações militares. (ANA, 2007).

O primeiro instrumento a contemplar a questão hídrica no Brasil encontra-se em documentos do reino, no Alvará de 1804, e aplicado ao Alvará de 1818. Desse documento consta que os rios navegáveis e caudais pertenciam ao reino, sendo, portanto, necessária a concessão do império para sua utilização. Também estabelece que as águas derivadas de rios e ribeiras podiam ser utilizadas por particulares, na indústria e para irrigação. (ALVARÁ de 1804, www.legis.senado.gov.br.).

Portanto, não surpreende que a Constituição Federal de 1824 tenha tratado a água de forma incipiente. No seu artigo 179 "assegura o direito de propriedade em toda a sua plenitude". Com isso, as águas de mananciais e subterrâneas pertenciam ao proprietário das terras. (CONSTITUIÇÃO FEDERAL, 1824).

A Constituição Republicana de 1891, igualmente, mostrou-se omissa quanto ao uso da água, não trouxe definições claras quanto a quem era de direito a propriedade dos rios. Apenas ressaltava no seu art. 34. $\S 6^{\circ}$ que era o Congresso Nacional quem tinha competência privativa para legislar sobre a navegação 


\section{OS DESAFIOS DA GEOGRAFIA FÍSICA NA FRONTEIRA DO CONHECIMENTO \\ Instituto de Geociências - Unicamp \\ Campinas - SP \\ 28 de Junho à 02 de Julho de 2017}

dos rios que banhassem mais de um Estado, ou sobre as águas que se estendessem a territórios estrangeiros. (CAMPANHOLE, 2000, p. 731-734).

Posteriormente foi editado o Código Civil de 1 de janeiro de 1916, intitulado "Dos Direitos de Vizinhança do Uso Nocivo da Propriedade", redigido um capítulo com seis artigos, do 563 ao 568, versando sobre as águas. Nele é considerada a utilização da água como um bem essencialmente privado e de valor econômico limitado, assegurando ao proprietário o usufruto dela, devendo apenas atentar-se a respeitar os direitos de vizinhança. Porém, o referido código não oferecia proteção às águas, nem determinava critérios amplos para o seu uso. (Código Civi de 1916).

No decorrer do tempo, foram criados outros instrumentos voltados para o gerenciamento das águas. Em 1933, a Comissão de Estudos das Forças Hidráulicas, integrada ao Serviço Geológico e Mineralógico do Ministério da Agricultura, foi convertida em Diretoria das Águas e no ano seguinte é agregada ao Departamento Nacional de Produção Mineral-DNPM.

A Constituição de 1934 apresentou outras competências para legislar as águas.

O artigo 20 § II- vislumbra sobre os bens de domínio da União "os lagos e quaisquer correntes em terrenos do seu domínio ou que banhem mais de um Estado, sirvam de limites com outros países ou se estendam a território estrangeiro; III - as ilhas fluviais e lacustres nas zonas fronteiriças". Enquanto o domínio do Estado são “- as margens dos rios e lagos navegáveis, destinadas ao uso público, se por algum título não forem do domínio federal, municipal ou particular. (Art. $21 \S$ II).

De modo geral, observa-se uma evolução na criação de instrumentos específicos para o gerenciamento das águas em todo o território brasileiro. Nesse bojo, merece destaque a criação do Código de Águas, (Decreto Federal n. ${ }^{\circ}$ 24.643, de 10 de julho de 1934), que efetuou a consolidação de legislação básica das águas no Brasil.

O Código de Águas foi considerado um avanço para os juristas daquela época, constituindo-se um marco legal no gerenciamento dos recursos hídricos do Brasil. Ele proíbe a contaminação das águas e, caso houvesse, os infratores deveriam ser punidos pelas perdas e danos, com o pagamento de multas e arcando com os custeios de salubridade das águas. Esse dispositivo pode ser visto como precursor do princípio de Poluidor-Pagador, o qual se encontra vigente nas leis brasileiras.

No referido código, ficou estabelecido que o uso de água corrente ou de nascente deve ser preferencialmente para abastecimento das populações. Determina, ainda, que a água pública necessita de concessão para a aplicação na agricultura, desde que não haja prejuízo de navegação, ou em outros casos deve ser destinado às primeiras necessidades de vida humana e de animais. O código tratou ainda de outros aspectos como: a força hidráulica, concessões, autorizações, desapropriação, fiscalização, 


\section{OS DESAFIOS DA GEOGRAFIA FÍSICA NA FRONTEIRA DO CONHECIMENTO \\ Instituto de Geociências - Unicamp \\ Campinas - SP \\ 28 de Junho à 02 de Julho de 2017}

navegação, águas nocivas, propriedade, domínio do solo e sua propriedade, aproveitamento, entre outros. (Código de Águas n. ${ }^{\circ}$ 24.643, 10/07/1934).

Cabe salientar que a promulgação do Código de Águas foi concomitante ao avanço do processo de industrialização do Brasil, conforme é ressaltado por Barbosa, (2007, p. 153):

Este Decreto-Lei ou Código de Águas foi editado com finalidade industrial, em especial, o desenvolvimento de energia hidráulica. Nesta época ainda não tinha sido incorporado o princípio ou fundamento dos 'usos múltiplos de águas', ou seja, apenas um setor, qual seja, industrial era privilegiado em detrimento dos outros setores, tais como agricultura, consumo humano, piscicultura, lazer, etc.

A primazia da geração de energia elétrica visava atender as indústrias, no momento em que o Brasil deixava de ser um país agrícola e caminhava para a industrialização. (HENKES, 2003).

A Constituição Federal de 1946 altera o domínio hídrico, atribui à União os lagos e quaisquer correntes de água em terrenos do seu domínio ou que banhem mais de um Estado, ou que sirvam de limite com outros países ou se estendam a território estrangeiro, enquanto confere aos Estados os lagos e rios em terrenos do seu domínio e os que têm nascente e foz no território estadual.

Na Emenda Constitucional de 1969, praticamente se reproduzem os termos da constituição anterior, incluindo entre os bens da União, além dos que à época lhe pertenciam, os lagos e quaisquer correntes de água em terrenos do seu domínio, ou que banhem mais de um Estado, constituam limite com outros países ou se estendam a território estrangeiro. Entre os bens dos Estados e dos Territórios, foram inseridos os lagos em terrenos do seu domínio, bem como os rios que neles têm nascente e foz.

Outro importante instrumento de gestão hídrica foi designado com a Política Nacional do Meio Ambiente-PNMA (Lei $\mathrm{n}^{\circ}$ 6.938/1981), que designou o Conselho Nacional de Meio Ambiente CONAMA. Esse órgão reforça os princípios jurídicos sobre a proteção das águas, estabelece normas, critérios e padrões relativos ao controle e qualidade do meio ambiente, com vistas ao uso racional dos recursos ambientais, principalmente os hídricos; incentiva a criação e estruturação de gestão de recursos ambientais e dos Comitês de Bacia Hidrográfica. Além disso, estabelece parâmetros sobre a qualidade das águas, dispõe sobre a classificação dos corpos de água e diretrizes ambientais para o seu enquadramento, que norteiam de forma segura o consumo de água dentro dos padrões de qualidade, bem como estabelece as condições e padrões de lançamento nos afluentes (Resolução CONAMA No 357/2005).

Da leitura dos dispositivos constitucionais até aqui abordados, emerge a constatação do avanço nas leis que regem a questão hídrica no Brasil. Entretanto, a Constituição Federal de 1988 merece notoriedade, na gestão das águas. 
XVII Simpósio Brasileiro

de Geografia Física Aplicada

I Congresso Nacional

de Geografia Física

\section{OS DESAFIOS DA GEOGRAFIA FÍSICA NA FRONTEIRA DO CONHECIMENTO \\ Instituto de Geociências - Unicamp \\ Campinas - SP \\ 28 de Junho à 02 de Julho de 2017}

\section{O papel da União e dos Estados na gestão da água-doce}

A concepção da água como recurso hídrico foi contemplada na Constituição Federal - CF de 1988 e trouxe uma inovação para o setor hídrico. Ela foi pioneira em extinguir o domínio das "águas privadas" de que tratava o Código das Águas.

Também sublinha que todo e qualquer recurso hídrico é um bem público, ou seja, é um bem coletivo, devendo estar disponibilizado com o intuito de promover o desenvolvimento econômico e social da nação. Além disso, a CF (88) delineou as competências dos entes federativos para legislar sobre as águas. (Henkes, 2003). É peculiaridade das constituições brasileiras, a partir de 1934, definir o domínio hídrico da União e dos Estados, enquanto a de 1988 declara bens da União.

Cabe destacar que a Constituição Federal vigente (1988) estabelece os recursos hídricos que estão sob a administração da União e estão delineados em seu art. 20: "III - os lagos, rios e quaisquer correntes de água em terrenos de seu domínio, ou que banhem mais de um Estado, sirvam de limites com outros países, ou se estendam a território estrangeiro ou dele provenham, bem como os terrenos marginais e as praias fluviais". Na leitura do texto constitucional acima transcrito, a União administra os recursos

hídricos nas terras que estão em seu domínio, bem como os recursos hídricos interestaduais ou internacionais, por meio da Agência Nacional de Águas. É importante frisar que, embora seja um tema controverso, as águas minerais são de domínio da União (art. 20, IX). Outra questão é que nem todos os rios e lagos estão sob o domínio da União, são apenas aqueles que banham mais de um estado.

Dessa forma, colocam-se entre os bens dos Estados federativos brasileiros "as águas superficiais ou subterrâneas, fluentes, emergentes e em depósito, ressalvadas, neste caso, na forma da lei, as decorrentes de obras da União;" (CF. 88, art. 26, I). Ademais, como as águas subterrâneas não são designadas para o domínio da União, incluem-se entre os bens dos Estados as águas subterrâneas circunscritas aos seus territórios, mesmo que elas se estendam em diferentes estados ou até mesmo países, como é o caso do Aquífero Guarany.

No Art. 22, IV da Constituição Federal de 1988, situa que compete privativamente à União legislar sobre águas. Porém, há que se considerar que a descentralização é exigida de forma federativa do Estado. Para esclarecer esse assunto, Cid Tomanik Pompeu, leciona que "no campo hídrico, a União tem dupla competência: (I) cria o direito sobre as águas, quando legisla privativamente; e (II) edita normas administrativas sobre as águas de seu domínio" (2010, p. 50). Dessa forma, aos demais entes federativos 
resta a competência para legislar editando normas administrativas sobre a gestão de suas águas. De tal modo, ao constituir normas para a emissão de Autorizações ou Concessões para uso de recursos hídricos (Outorgas), um determinado estado da federação brasileira está editando normas de segunda classe, na visão de Pompeu, (2010).

Sobre esse assunto, o art. 29 da Lei $n^{\circ} .9 .433$ de 1997 designa a competência privativamente da União para legislar as águas da seguinte forma: Compete ao Poder Executivo Federal tomar as providências necessárias à implementação e ao funcionamento do Sistema Nacional de Gerenciamento de Recursos Hídricos; outorgar o direito de usos e recursos hídricos, regular e fiscalizar o uso na sua esfera de competência, implantar e gerir o Sistema de informações sobre recursos hídricos, em âmbito nacional; promover a integração da gestão de recursos hídricos com a gestão ambiental. Por decreto, indicará a autoridade responsável pela efetivação de outorgas de direito de uso dos recursos hídricos sob domínio da União.

Quanto aos Estados e ao Distrito Federal compete outorgar os direitos de uso de recursos hídricos e regulamentar e fiscalizar os seus usos; realizar o controle técnico das obras de oferta hídrica;

implantar e gerir o Sistema de Informações sobre Recursos Hídricos, em âmbito estadual e do Distrito Federal; promover a integração da gestão de recursos hídricos com a gestão ambiental.

Em geral, a União concentra competência em matéria de recursos hídricos, entretanto, como já foi sublinhado, há espaço para os Estados da Federação criarem um regime de gestão das águas de forma racional e equilibrada. Sobre esse assunto Henkes (2003) traz a seguinte explanação: “[...] cabe à União legislar sobre o Direito das Águas, enquanto que aos Estados e ao Distrito Federal cabe legislar meramente de forma administrativa". Aliás, os governos estaduais têm aproveitado essa abertura na lei e têm desempenhado uma administração cabal nos rios que têm foz e nascente em seu território, mesmo quando esses rios desembocam em outros rios que fluem para outros estados.

Desde a década de 1970, foram surgindo experiências pioneiras no gerenciamento dos recursos hídricos, fundamentadas em bacias hidrográficas, em especial nas regiões Sul e no Sudeste brasileiro. Essas experiências evidenciavam a ausência de uma lei federal que desse conta de atender as demandas da sociedade. O sistema de gestão de bacias adotado no Brasil apresenta um arranjo administrativo que visa a conciliar os diversos interesses, controlar os conflitos e dividir as responsabilidades. (CUNHA e COELHO, 2012, p. 70). 
XVII Simpósio Brasileiro

de Geografia Física Aplicada

I Congresso Nacional

de Geografia Física
OS DESAFIOS DA GEOGRAFIA FÍSICA NA FRONTEIRA DO CONHECIMENTO

Instituto de Geociências - Unicamp

Campinas - SP

28 de Junho à 02 de Julho de 2017

Em consequência disso, diversos estados brasileiros foram criando políticas próprias para gestão hídrica como é o caso de São Paulo (Lei no 7.663/91); Ceará (Lei $n^{\circ}$ 11.996/92); Minas Gerais (Lei $n^{\circ}$ 11.504/94) e Rio Grande do Sul (Lei no 10.350/94).

Além disso, as experiências vividas pelo Ministério das Minas e Energia e pelo governo do Estado de São Paulo, para melhoria na qualidade das águas das bacias do Alto Tietê e Cubatão, serviram de incentivo para que outros modelos fossem implementados. Entre eles, configura-se o Comitê Especial de Estudos Integrados de Bacias Hidrográficas-CEEIBH e a criação de comitês em diversas bacias hidrográficas, como no Paraíba do Sul, no São Francisco e no Ribeira de Iguape, em 1978. Porém, esses comitês consideravam a estrutura burocrática do Estado e não contemplavam a participação da sociedade civil e dos usuários. (PORTO E PORTO, 2008).

Com o passar do tempo, o sistema paulista foi-se aprimorando e estabeleceu-se sua própria lei de gestão das águas (Lei nº 7.663, de 30 de dezembro de 1991). Essa lei estabeleceu normas e princípios para gestão dos recursos hídricos, servindo de modelo para projeto maior, como a Lei das Águas.

A promulgação da Lei das Águas (8 de janeiro de 1997, Lei Federal n ${ }^{9} .433$ ) veio suprir a escassez qualitativa e quantitativa no Brasil até a década de 1990, regulamentou o inciso XIX do artigo 21 da Constituição Federal (88), e criou o Sistema Nacional de Gerenciamento dos Recursos Hídricos.

Cabe ressaltar que uma das prerrogativas da Lei das Águas é o gerenciamento integrado dos recursos hídricos, o que está claramente fixado no inciso XIX do artigo 21 da Constituição Federal de 1988). Assim, adota-se a bacia hidrográfica como unidade de gestão, que é a unidade territorial para a implementação da Política Nacional de Recursos Hídricos-PNRH e de atuação do Sistema Nacional de Gerenciamento dos Recursos Hídricos-SNGRH. Embora não haja referência constitucional expressa à bacia hidrográfica, ela foi considerada pela Lei das Águas, a partir do modelo de gestão francês como a unidade territorial para a implementação da PNRH e a atuação do Singreh (Lei nº 9.433/1997, art. $1^{\text {o }}$, V).

Ademais, a Lei das Águas (nº 9.433 de 08 de janeiro de 1997) instituiu o Conselho Nacional de Recursos Hídricos-CNRH (lei 9.984, de 17 de julho de 2000, pelo Decreto $n^{\circ} 4.613$, de 11 de março de 2003), que por sua vez tem competência para formular políticas nacionais de recursos hídricos e estabelecer diretrizes complementares à sua implementação e aplicação de instrumentos para a atuação do Sistema Nacional de Gerenciamento de Recursos Hídricos-SNGRH. 
XVII Simpósio Brasileiro de Geografia Física Aplicada

I Congresso Nacional de Geografia Física

\section{OS DESAFIOS DA GEOGRAFIA FÍSICA NA FRONTEIRA DO CONHECIMENTO \\ Instituto de Geociências - Unicamp \\ Campinas - SP \\ 28 de Junho à 02 de Julho de 2017}

Os diversos órgãos que constituem esse sistema atuam de forma integrada e de forma horizontalizada. A tabela 1 nos apresenta um vislumbre de como está estruturado esse sistema.

Tabela 1- Sistema Nacional de Gerenciamento de Recursos Hídricos e Bacias Hidrográficas

\begin{tabular}{|l|l|l|l|l|}
\hline CNRH & $\begin{array}{l}\text { Formulação e } \\
\text { deliberação sobre } \\
\text { políticas de recursos } \\
\text { hídricos }\end{array}$ & $\begin{array}{l}\text { Formulação de } \\
\text { políticas } \\
\text { governamentais }\end{array}$ & Apoio aos colegiados & $\begin{array}{l}\text { Apoio Técnico (T) e } \\
\text { Regulação (R) }\end{array}$ \\
\hline Nacional & Conselho Nacional & $\begin{array}{l}\text { Ministério do Meio } \\
\text { Ambiente }\end{array}$ & SRHU e ANA & ANA (T e R) \\
\hline Estadual & Conselhos estaduais & Secretarias de Estado & $\begin{array}{l}\text { Órgãos gestores } \\
\text { estaduais Órgãos gestores } \\
\text { estaduais (T e R) }\end{array}$ \\
\hline $\begin{array}{l}\text { Bacia } \\
\text { Hidrográfica }\end{array}$ & Comitês de bacia & $\begin{array}{l}\text { Secretarias- ou } \\
\text { executivas } \\
\text { agências de Água }\end{array}$ & Agência de Água (T) \\
\hline
\end{tabular}

Fonte: ANA (2012)

Os órgãos que compõem o SNGRH comportam-se de forma descentralizada e são suas respectivas atribuições, a saber:

O Conselho Nacional de Recursos Hídricos - como organização mais alta da hierarquia do Sistema de Gestão dos Recursos Hídricos tem como diretor executivo o Ministro do Meio Ambiente e conta com representantes dos ministérios do Governo Federal, membros designados pelos Conselhos Estaduais de Recursos Hídricos e representantes de usuários de água e organizações civis relacionados com a gestão de recursos hídricos. Os Conselhos Estaduais apresentam uma organização com normas, critérios e procedimentos relativos ao Sistema Estadual de Gerenciamento de Recursos Hídricos;

Os Comitês de Bacias Hidrográficas - CBHs são compostos por representantes do Governo Federal, Estados ou do Distrito Federal onde se situam (mesmo que parcialmente), municípios, usuários da água e organizações civis de recursos hídricos com registro comprovado de ação na bacia. O número de representantes de cada setor mencionado e os critérios para suas nomeações são definidos nas regulamentações dos Comitês.

A respeito dos Comitês de Bacias, ANA (2012, p. 20) acrescenta: "os Comitês de Bacia Hidrográfica diferem de outras formas de participação previstas nas demais políticas públicas, pois têm como atribuição legal para deliberar sobre a gestão da água fazendo isso de forma compartilhada com o poder público". O comitê é quem define as regras a serem seguidas com relação ao uso das águas. A isso convenciona-se chamar de poder de Estado, envolvendo vários atores na tomada de decisão sobre um bem público. Essa nova concepção de gestão das águas exige mudança de atitudes para dividir o poder dos usuários e da sociedade civil, "a determinação para compartilhar responsabilidades". (ANA 2012, p. 20). 


\section{OS DESAFIOS DA GEOGRAFIA FÍSICA NA FRONTEIRA DO CONHECIMENTO \\ Instituto de Geociências - Unicamp \\ Campinas - SP \\ 28 de Junho à 02 de Julho de 2017}

Nesse sentido, as políticas públicas voltadas para os recursos hídricos são influenciadas pelas demandas vindas da sociedade.

Cabe salientar que bacia hidrográfica é um termo que já tem sido muito utilizado na Geografia Física. Alguns autores corroboram com a definição desse conceito como sendo uma "[...] área de drenagem de um rio principal e de seus tributários. As bacias são compostas de subsistemas (microbacias) e de diferentes ecossistemas (várzea, terra firme) etc." (Cunha e Coelho, 2012, p. 70). Em consonância com a definição apresentada, Barrela, (2001); Lima e Zakia, (2000) definem bacias hidrográficas como sendo um conjunto de terras drenadas por um rio e seus afluentes e como sistemas abertos interagem com outros elementos, como a água das chuvas, que recebem e as alimenta. No entanto, a delimitação das bacias hidrográficas nem sempre coincide com as delimitações da administração política. (CUNHA e COELHO 2012, p. 69-71).

A Agência Nacional de Águas -ANA, criada pela lei 9.984/2000 e regulamentada pelo decreto $\mathrm{n}^{\circ}$ 3.692/2000, é uma autarquia federal, cuja responsabilidade é implementar o Plano Nacional de Recursos Hídricos formulado pelo Conselho Nacional de Recursos Hídricos-CNRH. A ANA está vinculada ao Ministério do Meio Ambiente, mas tem independência financeira e administrativa, é composta por 10 superintendências funcionais com funções administrativas e de implementação, chefiadas por um presidente e quatro diretores. (ANA, 2012).

Em suma, a Lei das Águas traz como contribuição a definição da água como um bem finito e dotado de valor econômico. Estabelece instrumentos para o seu efetivo gerenciamento, priorizando mais aqueles de formulação e negociação, do que os de comando e controle, tradicionais centralistas de Estado. Além do mais, ela assegura a participação dos usuários de água e de representantes de segmentos da sociedade. Pode-se considerar que é uma evolução na gestão de um bem de domínio público, que enseja o exercício da gestão compartilhada (ROMANO et al, 2006).

Por fim, percebemos que, no âmbito de gestão hídrica no Brasil, transitam interesses ambientalistas e necessidades socioeconômicas. Isso revela que elas se configuram respectivamente numa ação conjunta do Estado com a sociedade civil no mundo contemporâneo.

\section{Considerações finais}

No discorrer desta pesquisa, foi possível observar a evolução da legislação voltada para a gestão dos recursos hídricos, tendo como marco a Constituição Federal de 1988, que no inciso XIX do artigo 21 


\section{OS DESAFIOS DA GEOGRAFIA FÍSICA NA FRONTEIRA DO CONHECIMENTO \\ Instituto de Geociências - Unicamp \\ Campinas - SP \\ 28 de Junho à 02 de Julho de 2017}

da CF/1988 presume a gestão integrada das águas no Brasil. Nesse aspecto, a Lei das Águas (n 9.433/97) regulamentou e criou o Sistema Nacional de Gerenciamento dos Recursos Hídricos.

O novo paradigma de gestão regulamentado pela Lei das Águas instituiu uma gestão compartilhada entre os entes federativos: a União, os Estados, Distritos Federal, cuja unidade de gestão é por bacia hidrográfica. Esse modelo encontra bastante espaço para sua viabilização, se apoiado de forma criativa nos instrumentos de gestão previstos na Lei ${ }^{\circ}$. 9.433/97.

Nesse aspecto há de se reconhecer que a Lei das Águas está inserida no novo modelo de Administração Pública brasileira, que é a gestão participativa, envolvendo usuários, planejadores e legisladores em todos os níveis, com vistas a atender aos interesses da coletividade.

Ademais, percebemos que a gestão hídrica até o momento atualizou-se e mesclou-se entre as diversas fases e faces, sendo influenciada pelas mudanças econômicas, sociais e políticas de cada tempo vivido.

\section{Bibliografia}

BARRELLA, W. et al. As relações entre as matas ciliares os rios e os peixes. In: RODRIGUES, R.R.; LEITÃO FILHO; H.F. (ORG). Matas ciliares: conservação e recuperação. 2. ed. São Paulo: Editora da Universidade de São Paulo, 2001.

BARBOSA, Erivaldo Moreira. Introdução ao direito ambiental. Campina Grande: EDUFCG, 2007. CAMPANHOLE, Adriano; CAMPANHOLE, Hilton Lobo. Constituições do Brasil: Compilação e atualização dos textos, notas, revisão e índices. São Paulo: Atlas, 2000.

CUNHA, S.; COELHO, M. C. Política e gestão ambiental. In: CUNHA, S. \& GUERRA, A. (Orgs). A questão ambiental. Diferentes abordagens. 7 $^{\mathrm{a}}$ edição. Rio de Janeiro: Bertrand Brasil, 2012.

HENKES, Silviana Lúcia. Gestão dos Recursos Hídricos: Acertos e Erros na Bacia Hidrográfica do Rio Itajaí/SC - Brasil. Dissertação (Mestrado em Engenharia de Produção) - UFSC, Florianópolis, 2002.

LANNA, Antonio Eduardo Leão. Gerenciamento de bacia hidrográfica: aspectos conceituais e metodológicos. Brasília: Instituto Brasileiro do Meio Ambiente e dos Recursos Naturais Renováveis, 1995.

POMPEU, Cid Tomanik. Direito das Águas no Brasil. São Paulo. Ed. Revista dos Tribunais, 2010.

PORTO, M. F. A.; PORTO, R. L. L. Gestão de bacias hidrográficas. In: Revista Estudos Avançados: Dossiê Água. Instituto de Estudos Avançados da USP. V. 33, nº 63, mai-ago/2008, p. 43-60.

RIBEIRO, Wagner Costa. A Ordem ambiental internacional. São Paulo: Contexto, 2010.

ROMANO, E.; ROMANO, P. A.; FEITOSA, V. M. N. Gestão descentralizada e participativa dos recursos hídricos e a mineração: riscos e oportunidades. In: Agência Nacional de Águas. A gestão dos 
recursos hídricos e a mineração. ANA/IBRAM (org.: Antônio Félix Domingues, Patrícia Helena Gambogi Boson e Suzana Alípaz). Brasília: ANA, 2006, p. 51-67.

\section{Leis e sites}

A política nacional de recursos hídricos. LEI $\mathrm{n}^{\circ}$ 9.433, de 08 de janeiro de 1997. Disponível em: www.planalto.gov.br/ccivil_03/leis/19433.htm. Acesso em: dezembro de 2015.

Agência Nacional de Energia Elétrica - ANEEL. LEI No 9.427, DE 26 DE DEZEMBRO DE 1996. Disponível em: http://www2.aneel.gov.br/cedoc/lei19969427. Acesso em: dezembro de 2016.

Código Civil- Planalto. LEI No 3.071, DE $1^{\circ}$ DE JANEIRO DE 1916. (Revogada pela Lei $\mathrm{n}^{\circ}$ 10.406, de 2002.) Disponível em: planalto.gov.br/ccivil_03/leis/2002/L10406.htm. Acesso em: janeiro de 2017.

Agência Nacional de Água- ANA. Disponível em: www.cbcs.org.br/livroagencianacionalde aguas, 2007. Acesso em: fevereiro 2016.

BRASIL. Constituição da República Federativa do Brasil. Brasília, DF: Senado, 1988. Disponível em: http://www.planalto.gov.br. Acesso em: 10 de novembro de 2015.

de 2016.

Constituição Federal de 1824. Dispnível em: hppt//www.planalto.gov.br/ccivil_03/ . Acesso em: fevereiro

Política Nacional do Meio Ambiente. Lei 6.938, de 31 de agosto de 1981. Disponível em: http://www.planalto.gov.br. Acesso em: 10 de novembro de 2015.

Agência Nacional de Águas. Panorama da qualidade das águas superficiais do Brasil: 2012/. Brasília: ANA, 2012. Disponível em: arquivos.ana.gov.br/institucional/pdf. Acesso em: janeiro de 2017.

CONAMA. Classificação dos corpos de água. Resolução do CONAMA No 357 / 2005. Disponível em: www.mma.gov.br/port/conama/legiabre.cfm. Acesso em março de 2016.

Departamento Nacional de Águas e Energia - DNAE. Lei $\mathrm{n}^{\circ}$ 4.904, de 17 de dezembro de 1965. Disponível em: www.planalto.gov.br/ccivil_03/leis/1950-1969/L4904.htm. Acesso em: janeiro de 2017.

Instituto Brasileiro de Geografia e Estatística- IBGE.Disponível em: Htt:// www.ibge.gov.br. Acesso em: outubro de 2016.

Recursos hídricos do Ceará. Lei $\mathrm{N}^{\circ}$ 11.996, de 24 de Julho de 1992.pdf - $\mathbf{n}^{\circ}$ 12.664. Disponível em: www.srh.ce.gov.br/index.php/legislação. Acesso em: marco de 2016.

Recursos hídricos de Minas Gerais. Lei no 11.504/94. Disponível em: https://www.almg.gov.br/consulte/legislacao. Acesso em: fevereiro de 2016.

Recursos hídricos do rio Grande do Sul. Lei Lei no 10.350/94. Disponível em: www.al.rs.gov.br/filerepository/repLegis/arquivos/10.350.pdf. Acesso em: fevereiro de 2016.

Orientação à Política Estadual de Recursos Hídricos bem como ao Sistema Integrado de Gerenciamento de Recursos Hídricos. Lei n ${ }^{\circ}$ 7.663, de 30 de dezembro de 1991. Disponível em: http://www.al.sp.gov.br. Acesso em: fevereiro de 2017.

Sistema Estadual de Recursos Hídricos, regulamentando. LEI No 10.350, DE 30 DE DEZEMBRO DE 1994. Publicado no DOE de 01/01/95. Rio Grande do Sul. Disponível em: http://mundoambiente.eng.br. Acesso em: 10 janeiro de 2017.

Criação da Agência Nacional de Água - ANA. LEI N ${ }^{\circ}$ 9.984, de 17 de Julho de 2000.Disponível em: www2.camara.leg.br/legin/fed/lei. Acesso em: 08 de janeiro de 2017. 


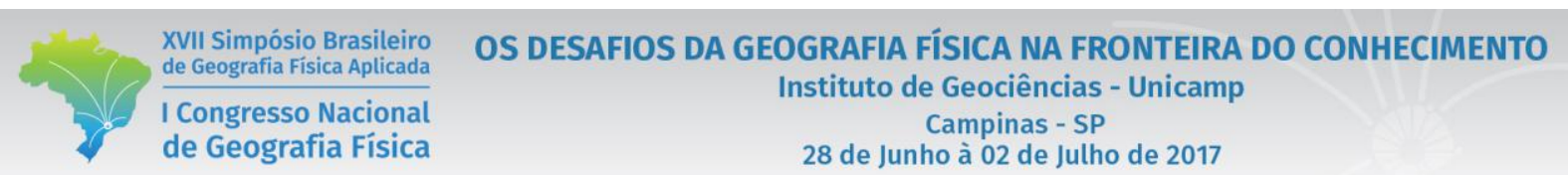

Decreto $\mathrm{n}^{\circ}$ 4.613, de 11 demarço de 2003. Regulamenta o Conselho Nacional de Recursos Hídricos. Disponível em: http://www.planalto.gov.br. Acesso em: 20 de janeiro de 2017.

DECRETO $\quad \mathrm{N}^{\mathrm{O}}$ 24.645, DE $10 \quad \mathrm{DE} \quad \mathrm{JULHO}$ DE $1934 . \quad$ Disponível em: http://www.planalto.gov.br/ccivil_03/decreto/1930-1949/D24645.htm. Acesso em: janeiro de 2017.

Ministérios da Indústria e do Comércio e das Minas e Energia, e dá outras providências. Lei $\mathrm{n}^{\circ}$ 3.782, de 22 de Julho de 1960. Disponível em: http://www.planalto.gov.br/CCivil_03/leis/1950-1969/L3782.htm. Acesso em: dezembro de 2016.

Senado Federal - Atividade Legislativa - Legislação - Constituição Federal de 1988. Disponível em: https://www.senado.gov.br/atividade/const/constituicao-federal.asp. Acesso em: janeiro de 2017. 